\title{
Carbonated hydroxyapatite starting from calcite and different orthophosphates under moderate hydrothermal conditions: Synthesis and surface reactivity in simulated body fluid
}

\author{
Doan Pham Minh *, Ange Nzihou, Patrick Sharrock \\ Université de Toulouse, Mines Albi, CNRS UMR 5302, Centre RAPSODEE, Campus Jarlard, F-81013 Albi cedex 09, France
}

\author{
A B S T R A C T
}

The one-step synthesis of carbonated hydroxyapatite (CAP) using calcite and different orthophosphates was investigated in a closed batch reactor. Only orthophosphoric acid could lead to the complete decomposition of calcite particles, when the reaction temperature was set at $80^{\circ} \mathrm{C}$. On the other hand, the reaction time and the dilution of the initial calcite suspension had no significant influence on the formation of the solid products. CAP was formed as the main crystalline calcium phosphate with the carbonate content in the range of 4.2-4.6 wt.\%. The thermal decarbonation of the synthesized CAP started at $750^{\circ} \mathrm{C}$ but it was only significant at $1000^{\circ} \mathrm{C}$ under air atmosphere. This thermal decarbonation was total at $1200^{\circ} \mathrm{C}$ or above. All CAP samples and products following thermal treatments were found bioactive in the test using simulated body fluid (SBF) solution.

Keywords:

Structural materials

Chemical synthesis

Infrared spectroscopy

Surface properties

\section{Introduction}

The inorganic mineral phase of human teeth and bone is mainly composed of calcium hydroxyapatite (Ca-HA, $\left.\mathrm{Ca}_{10}\left(\mathrm{PO}_{4}\right)_{6}(\mathrm{OH})_{2}\right)$, with different substitutions such as sodium, magnesium, chloride, fluoride, carbonate, etc. [1-3]. This explains the interest in the development of $\mathrm{Ca}-\mathrm{HA}$ and substituted $\mathrm{Ca}-\mathrm{HA}$ in the biomaterials field, due to their biocompatibility and bioactivity $[4,5]$. Substituted Ca-HA is formed when calcium, phosphate, and/or hydroxyl groups of Ca-HA structure are replaced by other metals and functional groups. Thus, bone mineral has usually the molar ratio of calcium to phosphate varying in the range of 1.37-1.87 compared with that of 1.67 for stoichiometric Ca-HA [3]. In general, carbonate is found to be the most abundant substitution and its content in bone mineral varies in the range of 3-8 wt.\% [6]. Carbonate groups can insert in the apatitic structure by replacing phosphate and/or hydroxyl groups to form carbonated hydroxyapatite (CAP). Conventionally, CAP is A-type CAP when carbonate groups replace phosphate groups; B-type CAP when carbonate groups replace hydroxyl groups; and A-B-type CAP when carbonate groups replace simultaneously phosphate and hydroxyl groups.

The synthesis of CAP calls usually for the classical wet and dry methods. In the wet process, soluble calcium and phosphates are

\footnotetext{
* Corresponding author. Tel.: +33 563493258; fax: +33 563493043.

E-mail address: doan.phamminh@mines-albi.fr (D. Pham Minh).
}

precipitated in an aqueous solution in the presence of carbonate anions $[7,8]$. This process leads generally to the formation of B-type CAP [7] but A-B-type CAP may be also formed [9]. In the dry process, A-type CAP could be generated by heating pure Ca-HA under $\mathrm{CO}_{2}$ flux at high temperature in order to replace hydroxyl groups by carbonate groups [10]. CAP could be also obtained by the common mechano-chemical process as demonstrated by Suchanek et al. [11], wherein an aqueous suspension of $\mathrm{Ca}(\mathrm{OH})_{2}$ and $\mathrm{CaCO}_{3}$ (or $\mathrm{Na}_{2} \mathrm{CO}_{3}$ ) and $\left(\mathrm{NH}_{4}\right)_{2} \mathrm{HPO}_{4}$ are treated in a laboratoryscale mill. But this last way requires severe reaction conditions.

We recently developed a new one-step synthesis process of Ca-HA from $\mathrm{CaCO}_{3}$ and orthophosphoric acid $\left(\mathrm{H}_{3} \mathrm{PO}_{4}\right)$ as economical starting materials at moderate synthesis conditions [12]. The advantage of this process compared to classical Ca-HA synthesis pathways remains in the fact that pure Ca-HA can be obtained without any further purification step, thanks to the absence of all counter ions in the reaction medium [12]. A modification of this process was then developed for the one-step synthesis of CAP under moderate hydrothermal conditions [13]. CAP containing $4.2 \mathrm{wt} . \%$ of carbonate could be obtained from the reaction of $\mathrm{CaCO}_{3}$ and $\mathrm{H}_{3} \mathrm{PO}_{4}$ in a close batch reactor under $\mathrm{CO}_{2}$ pressure. $\mathrm{CaCO}_{3}$ was chosen because it is the source of both calcium cations and carbonate anions for the formation of CAP, and also because it has considerable industrial importance and abundant diversity as a biomineral [14]. In this work, we firstly compared the reaction of calcite with different alkali orthophosphates and orthophosphoric acid in order to select the best orthophosphate. Then, we investigated the influence of different 
Table 1

Synthesis conditions of CAP from $\mathrm{CaCO}_{3}(100 \mathrm{mmol}$ or $10 \mathrm{~g}$ ), alkali orthophosphates, and $\mathrm{H}_{3} \mathrm{PO}_{4}(66.7 \mathrm{mmol}) ; \mathrm{D}$ is the mass ratio of water to calcite in the initial suspension. The final pressure in the batch reactor varied in the range of 9-16 bar.

\begin{tabular}{lllllll}
\hline Orthophosphate & $\begin{array}{l}T \\
\left({ }^{\circ} \mathrm{C}\right)\end{array}$ & $\begin{array}{l}t \\
(\mathrm{~h})\end{array}$ & $D$ & $\begin{array}{l}\text { Water } \\
(\mathrm{g})\end{array}$ & $\begin{array}{l}\text { Solid product } \\
\text { designation }\end{array}$ & Note \\
\hline $\mathrm{NaH}_{2} \mathrm{PO}_{4}$ & 80 & 48 & 13.5 & 135 & CAP-Na & Comparison of \\
$\mathrm{KH}_{2} \mathrm{PO}_{4}$ & 80 & 48 & 13.5 & 135 & CAP-K & orthophosphate \\
$\mathrm{NH}_{4} \mathrm{H}_{2} \mathrm{PO}_{4}$ & 80 & 48 & 13.5 & 135 & CAP-N & \\
$\mathrm{H}_{3} \mathrm{PO}_{4}$ & 80 & 48 & 13.5 & 135 & CAP-H & \\
& & & & & & \\
$\mathrm{H}_{3} \mathrm{PO}_{4}$ & 60 & 48 & 4.5 & 45 & T60/t48/D4.5 & Parametric \\
$\mathrm{H}_{3} \mathrm{PO}_{4}$ & 60 & 48 & 9 & 90 & T60/t48/D9 & study \\
$\mathrm{H}_{3} \mathrm{PO}_{4}$ & 80 & 48 & 4.5 & 45 & T80/t48/D4.5 & \\
$\mathrm{H}_{3} \mathrm{PO}_{4}$ & 80 & 48 & 9 & 90 & T80/t48/D9 & \\
$\mathrm{H}_{3} \mathrm{PO}_{4}$ & 80 & 168 & 9 & 90 & T80/t168/D9 & \\
\hline
\end{tabular}

parameters including the content of water in the initial suspension of $\mathrm{CaCO}_{3}$, the reaction temperature and the reaction time, on the content of carbonate inserted in the final solid CAP. The in vitro biomineralization activity of the solid CAP product containing the highest carbonate content was also investigated before and after thermal treatment at different temperatures.

\section{Materials and methods}

Orthophosphoric acid $\left(\mathrm{H}_{3} \mathrm{PO}_{4}, 85 \mathrm{wt}\right.$.\% in water) was purchased from Merck. Calcite powder $\left(\mathrm{CaCO}_{3}, \mathrm{~d}_{50}\right.$ of $\left.23.6 \mu \mathrm{m}\right)$, and alkali orthophosphates $\left(\mathrm{NaH}_{2} \mathrm{PO}_{4}, \mathrm{KH}_{2} \mathrm{PO}_{4}, \mathrm{NH}_{4} \mathrm{H}_{2} \mathrm{PO}_{4}\right)$ of analytical purity from Fisher Scientific were used as received without further purification. The reaction of $\mathrm{CaCO}_{3}$ with these orthophosphates was carried out in a $250 \mathrm{~mL}$ stainless steel close batch reactor (Top Industry, France) which was equipped with an electrical heating jacket and a magnetic stirrer. When orthophosphoric acid was used, $10 \mathrm{~g}$ of calcite powder and 45-135 g of water were fed into the reactor. The reactor was closed and then $6.92 \mathrm{~g} \mathrm{H}_{3} \mathrm{PO}_{4}(85 \mathrm{wt}$.\%) was quickly injected into the reactor via a syringe. When alkali orthophosphates were used, $10 \mathrm{~g}$ of water was set into the reactor. This last one was closed and $135 \mathrm{~g}$ of an aqueous solution containing $60 \mathrm{mmol}$ of an alkali orthophosphate was quickly injected into the reactor. In all case, the molar ratio of calcium to phosphorus in the initial reaction mixture was 1.67 . The reaction mixture was kept at 60 or $80^{\circ} \mathrm{C}$ under stirring of $800 \mathrm{rpm}$ for $48-168 \mathrm{~h}$ of reaction. The conditions for the synthesis of different CAP were summarized in Table 1. During the reaction, the pressure in the batch reactor was measured by a manometer. When the reaction reached the desired reaction time, the reactor was freely cooled down to room temperature. Solid products were separated from liquid phase by filtration using $0.45 \mu \mathrm{m}$ filter paper. Then they were air-dried at $50^{\circ} \mathrm{C}$ for $48 \mathrm{~h}$ before further analyses and characterizations.

Elemental analysis was carried out by inductively coupled plasma atomic emission spectroscopy (ICP-AES, HORIBA Jobin Yvon Ultima 2 apparatus). Infrared spectroscopy (IR) was carried out using a Shimadzu FTIR 8400 S spectrometer in the wavenumber range $4000-500 \mathrm{~cm}^{-1}$. X-ray diffraction (XRD) measurements were carried out using a Phillips Panalytical X'pert Pro MPD diffractometer. Scanning electron microscopy (SEM) observation was performed on a Philips XL30 ESEM apparatus. Thermogravimetry analysis (TG) was carried out with a SDTQ600 analyzer (TA Instruments) under air flow $\left(100 \mathrm{~mL} \mathrm{~min}^{-1}\right)$ with the heating rate of $20^{\circ} \mathrm{C} \mathrm{min}^{-1}$. The amount of remaining $\mathrm{CaCO}_{3}$ in the final solid was calculated corresponding to the observed weight loss of $\mathrm{CO}_{2}$ from 610 to $720^{\circ} \mathrm{C}$.

\section{Results}

\subsection{Orthophosphate comparison}

Fig. 1 presents XRD results of the solid products obtained from the reaction of calcite with four orthophosphates under similar reaction conditions. In all cases, Ca-HA appeared as the main crystalline calcium phosphate. On the other hand, the decomposition of calcite was different from each other orthophosphate. Under the reaction conditions used, orthophosphoric acid allowed decomposing completely the introduced calcite, because the signal of the main diffraction peak of calcite at $29.4^{\circ}$ was negligible (CAP-H pattern). For three alkali orthophosphates used, diffraction peaks of remaining calcite were clearly observed, which indicates that the reaction of calcite and these

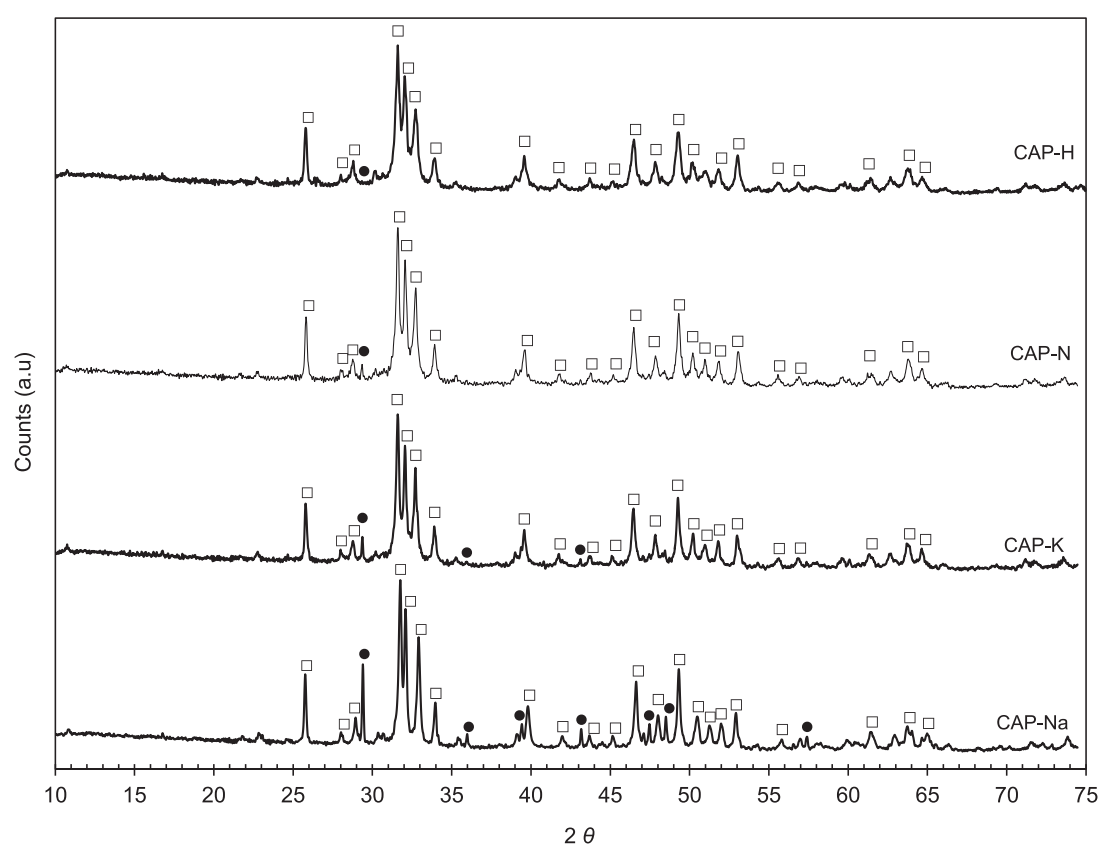

Fig. 1. XRD patterns of the solid products obtained from the reaction of calcite with different orthophosphates at $80{ }^{\circ} \mathrm{C}$ in close batch reactor. 


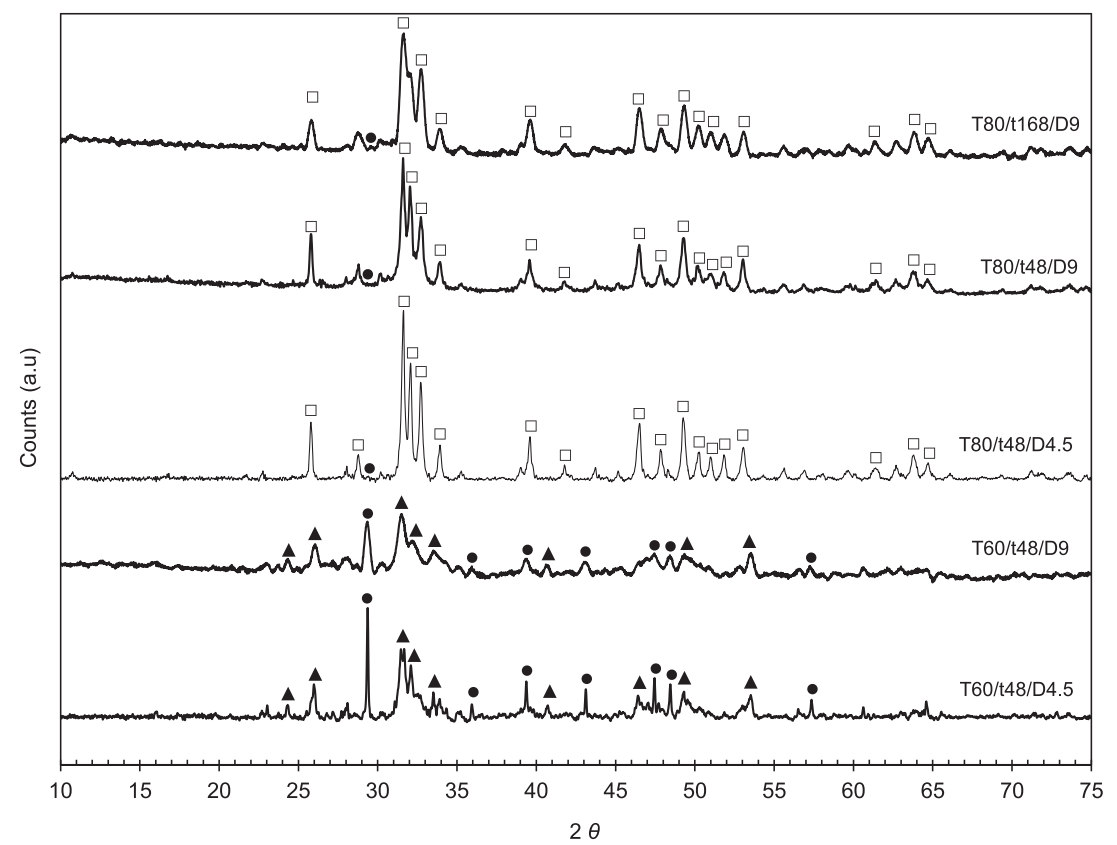

Fig. 2. XRD patterns of the solid products obtained at different synthesis conditions; ( $\square$ ) Ca-HA (JCPDS standard No. 01-072-1243); ( $\mathbf{\Delta}$ ) OCP (JCPDS standard No. 00-0261056); (๑) calcite (JCPDS standard No. 00-047-1743).

orthophosphates was not completed. This result was confirmed by TG analysis (results not shown). The remaining calcite content present in the final solids was 4.4, 1.4, 0.5 and $<0.06$ wt.\% for CAP$\mathrm{Na}, \mathrm{CAP}-\mathrm{K}, \mathrm{CAP}-\mathrm{N}$ and CAP-H, respectively. Probably, orthophosphoric acid with higher acidity compared to other alkali orthophosphates was more favorable for the dissolution of calcite particles, which is crucial for the formation of calcium phosphate phases [15]. When calcite particles were covered by solid calcium phosphate layers, the contact between these covered calcite particles and orthophosphates sources must be prevented and so the reaction is stopped or slowed down $[15,16]$. In addition to this higher performance for the decomposition of calcite, no washing step was needed for the purification of the solid product starting from orthophosphoric acid thanks to the absence of counter-ions such as alkalis. So for the next parametric study, CAP synthesis was performed only with orthophosphoric acid.

\subsection{CAP from calcite and orthophosphoric acid - XRD characterization}

Fig. 2 presents XRD patterns of the solid products obtained at different synthesis conditions. Both products obtained at $60^{\circ} \mathrm{C}$ (T60/t48/D4.5 and T60/t48/D9) contained octocalcium phosphate (OCP, $\left.\mathrm{Ca}_{8}\left(\mathrm{HPO}_{4}\right)_{2}\left(\mathrm{PO}_{4}\right)_{4} \cdot 5 \mathrm{H}_{2} \mathrm{O}\right)$ as the main crystalline calcium phosphate, and high contents of remaining calcite. So the temperature of $60^{\circ} \mathrm{C}$ was not enough for the complete dissolution of calcite particles. Probably this temperature led to the formation of core-shell particles in which calcite core was covered by solid calcium phosphate layers (shell) [17]. This structure prevented the

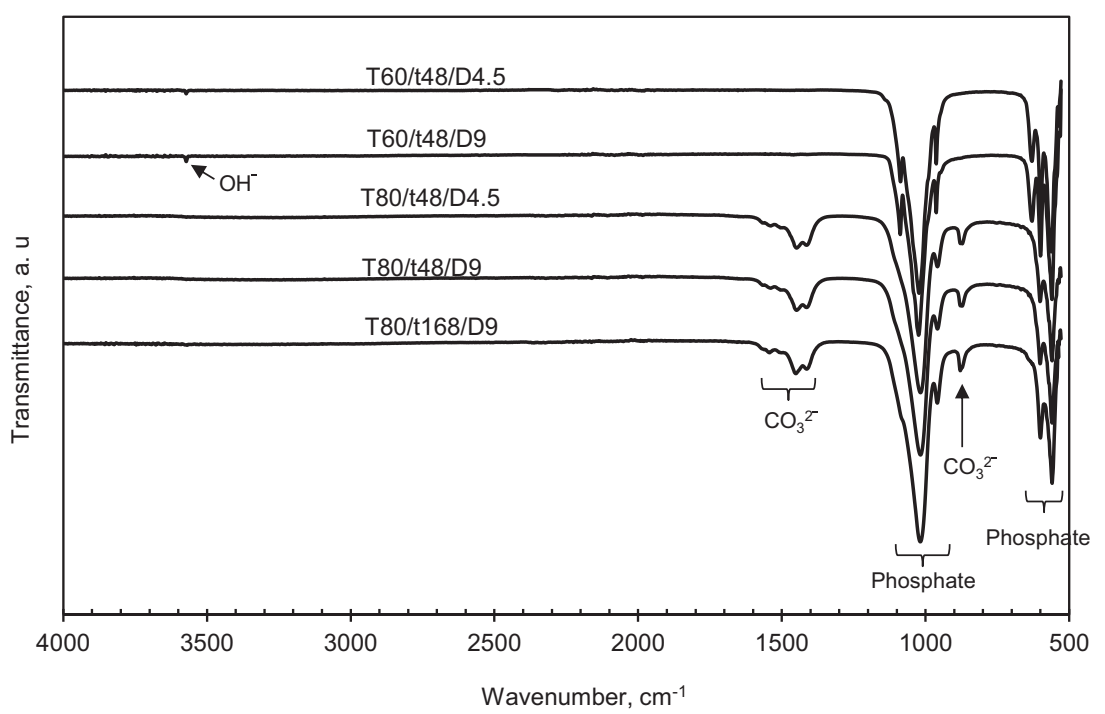

Fig. 3. IR spectra of all the solid products. 
contact of remaining calcite core with phosphate species and slowed down or stopped the reaction at this temperature. The increase of the dilution of calcite suspension did not improve the dissolution of calcite at $60^{\circ} \mathrm{C}$.

On the other hand, when the reaction temperature rose to $80^{\circ} \mathrm{C}$, calcite could be completely dissolved as indicated its very weak signal of the principal XRD peak at $29.4^{\circ}$. At this temperature and for the same reaction time of $48 \mathrm{~h}$, the dilution of $\mathrm{CaCO}_{3}$ suspension had no remarkable influence on the formed product. The main crystalline calcium phosphate phase identified for the products synthesized at $80^{\circ} \mathrm{C}$ was $\mathrm{Ca}-\mathrm{HA}$. However, CAP (JCPDS standard No. 96-900-3550, 96-900-3551, 96-900-3552) might be also present in these products but their XRD diffractions are usually superposed on those of Ca-HA. So the presence of CAP needs to be confirmed by other analyses.
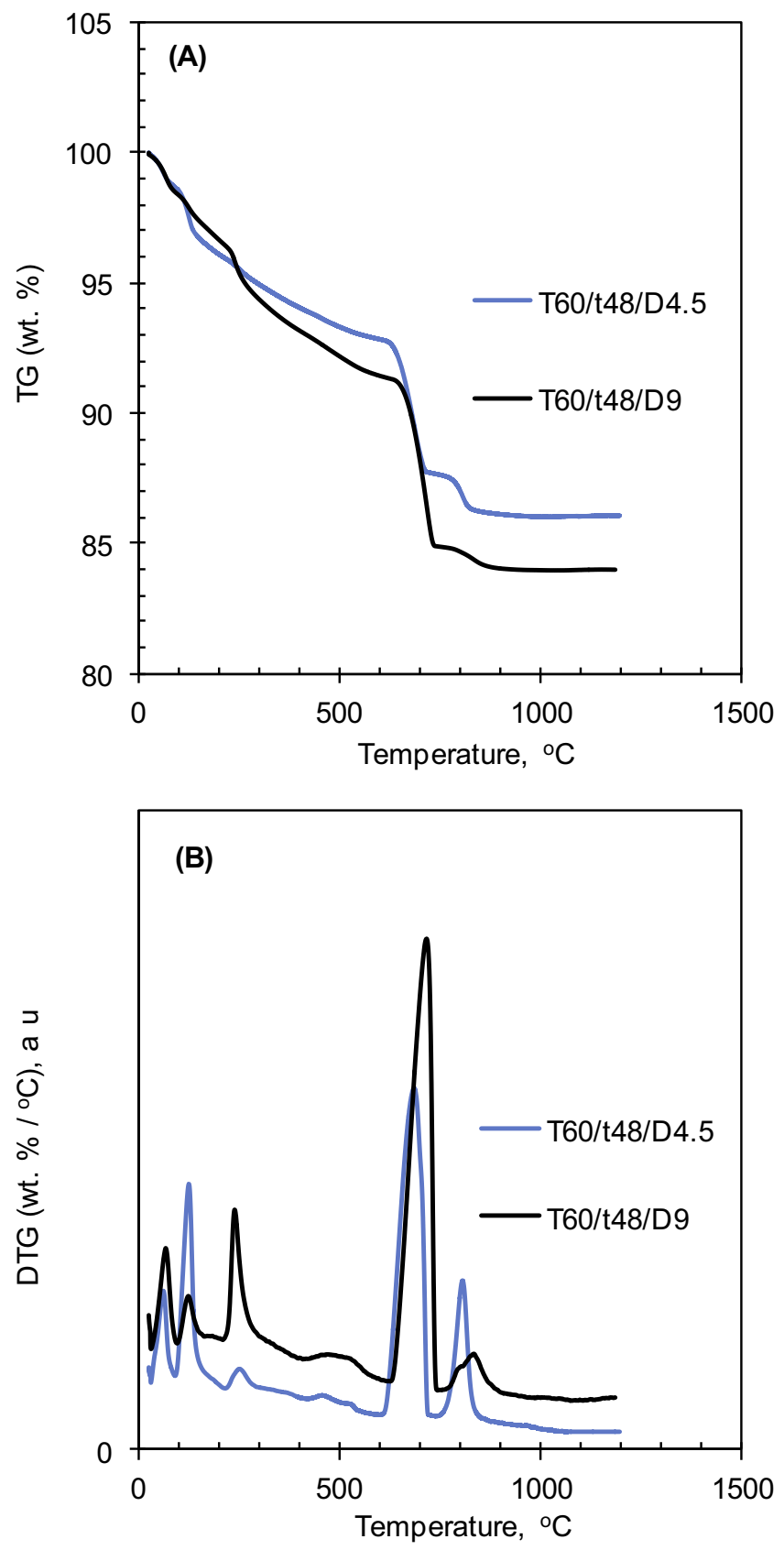

Fig. 4. TG analysis of the solid products synthesized at $60^{\circ} \mathrm{C}$.

\subsection{CAP from calcite and orthophosphoric acid - IR characterization}

IR spectra of all the solid products are presented in Fig. 3. In all cases, characteristic peaks of phosphate groups could be found in the wavelength ranges of $650-550 \mathrm{~cm}^{-1}$ and $1300-910 \mathrm{~cm}^{-1}$ [13]. For two solids obtained at $60^{\circ} \mathrm{C}$, no signal of carbonate groups was observed, despite remarkable contents of remaining calcite as shown by XRD analysis (Fig. 2). As mentioned above, calcite remnants must be covered by calcium phosphate layers and therefore could not be detected by diffuse reflectance IR analysis, which records only surface information for solid samples.

For the solids synthesized at $80^{\circ} \mathrm{C}$, absorption bands of carbonate groups could be clearly observed at $1545,1450,1415$, 880 , and $870 \mathrm{~cm}^{-1}$. All these absorption bands could be attributed to carbonate groups inserted in the apatite structure of Ca-HA

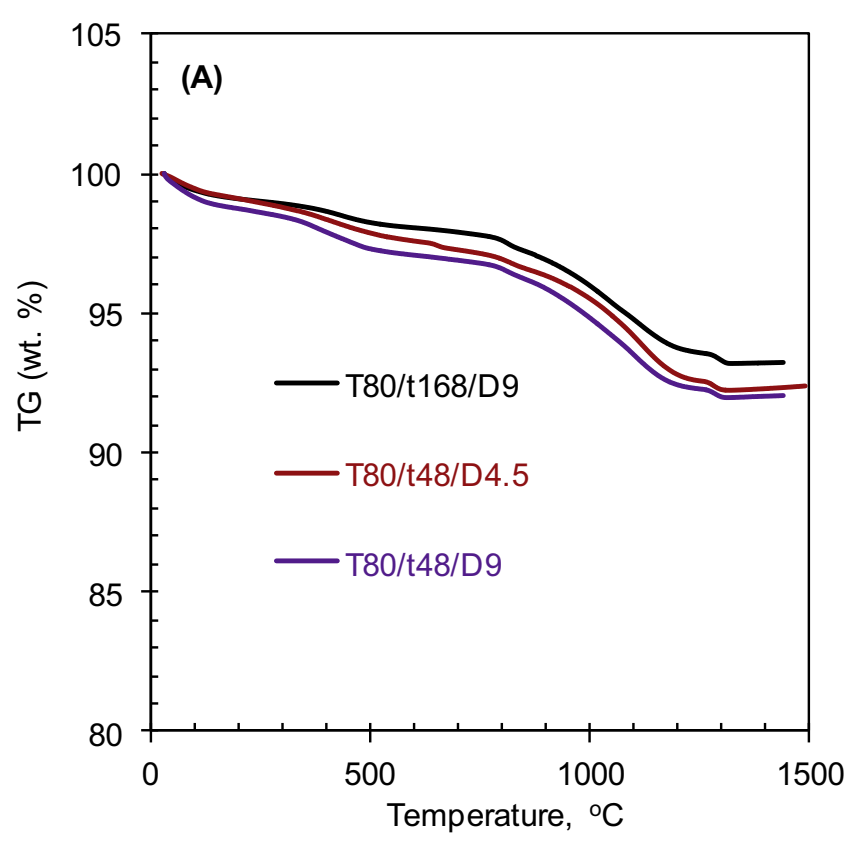

(B)

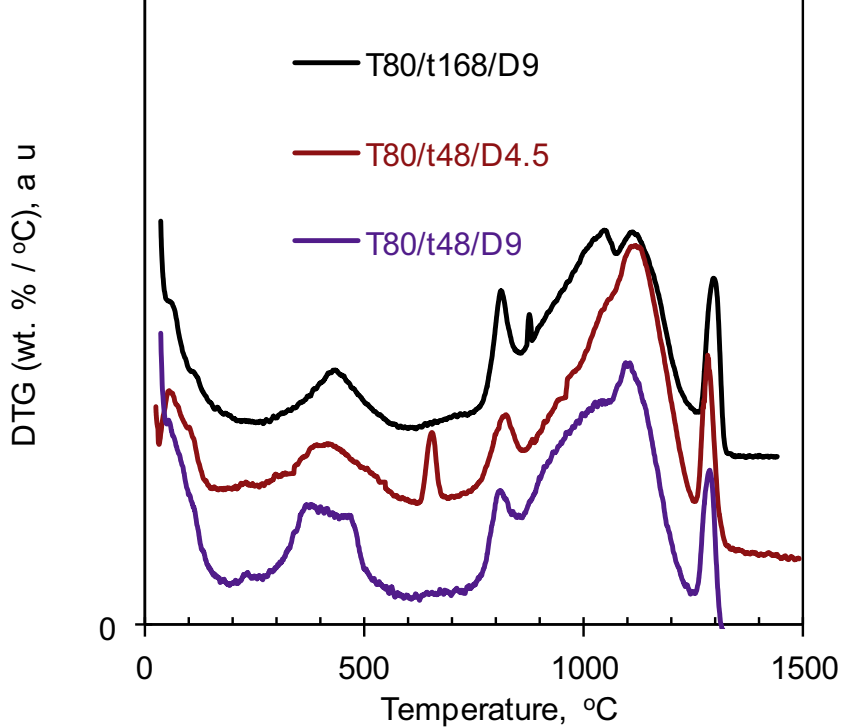

Fig. 5. TG analysis of the solid products synthesized at $80^{\circ} \mathrm{C}$. 


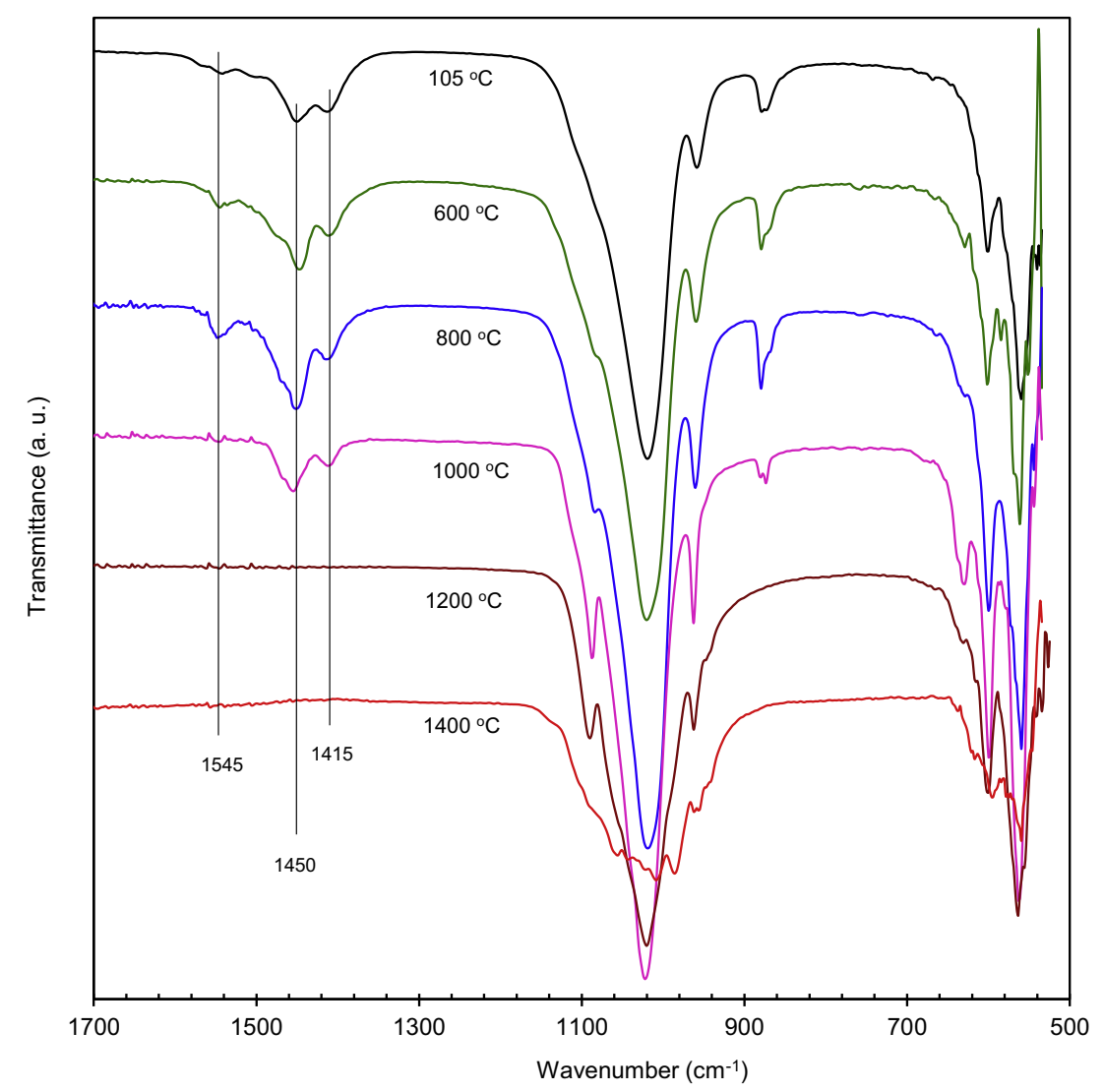

Fig. 6. IR spectra of T80/t48/D4.5 after thermal treatment at different temperatures.

[18-20]. Carbonate groups replaced both phosphate and hydroxyl groups to form A-B-type CAP, as illustrated by their characteristic absorption bands at 1545 and $880 \mathrm{~cm}^{-1}$ (A-type) and 1450 , 1415 and $870 \mathrm{~cm}^{-1}$ (B-type) [18,19].

The elemental analysis of three solid products obtained at $80^{\circ} \mathrm{C}$ showed that the molar ratio of calcium to phosphorus varied in 1.83-1.90 range, which was higher than the value of the stoichiometric Ca-HA. This can be explained by the insertion of carbonate groups at the position of phosphate groups.

\subsection{CAP from calcite and orthophosphoric acid - TG characterization}

For the use as biomaterials, calcium phosphate based products are usually treated by a sintering step [21]. Thermal behavior of the prepared solids was investigated in large range of temperature as shown in Figs. 4 and 5 . For the solid prepared at $60^{\circ} \mathrm{C}$ (Fig. 4), after the first weight loss about $100^{\circ} \mathrm{C}$ due to the removal of surface humidity, different weight losses in the temperature range of $100-600^{\circ} \mathrm{C}$ were observed for the dehydration of OCP $[18,22-25]$, which was the main calcium phosphate present in these solids. Remaining calcite showed an intense weight loss at about $610^{\circ} \mathrm{C}$, followed by the decarbonation of CAP at $750^{\circ} \mathrm{C}$. No further weight loss was observed up to $1200^{\circ} \mathrm{C}$ for these two solids.

For the solids synthesized at $80^{\circ} \mathrm{C}$, after the dehydration of surface moisture around $100^{\circ} \mathrm{C}$, the dehydration of hydrogenophosphate groups took place in the range of $100-600^{\circ} \mathrm{C}$. These weight losses were much lower compared to the solids synthesized at $60^{\circ} \mathrm{C}$ (Fig. 4). As expected, no notable signal of calcite decomposition was detected around $610^{\circ} \mathrm{C}$. On the other hand, the decarbonation of CAP took place with important weight losses. This decarbonation started at about $750^{\circ} \mathrm{C}$ and finished at about $1200^{\circ} \mathrm{C}$. The last weight loss around $1250^{\circ} \mathrm{C}$ was due to the dehydration of hydroxyl group of apatitic structure to form oxyhydroxyapatite [5]. So, when the synthesis temperature was set at $80^{\circ} \mathrm{C}$, the reaction time and the dilution of the initial calcite suspension had no notable influence on the final CAP. Three solid products synthesized at $80^{\circ} \mathrm{C}$ seemed also to have similar thermal behavior. From TG analysis, the content of carbonate inserted in the apatitic structure could be calculated, supposing that weight loss in the temperature range of $750-1250$ was due to the thermal decarbonation. Thus, three solid products synthesized at $80^{\circ} \mathrm{C}$ from calcite and orthophosphoric acid had the carbonate content in the range of $4.2-4.6 \mathrm{wt} . \%$.

3.5. CAP from calcite and orthophosphoric acid - thermal treatment and biomineralization activity in SBF solution

For use as biomaterials, hydroxyapatite based products, including CAP, may need stabilization step by thermal treatment. In the case of CAP, the thermal treatment should not lead to deep decarbonation, in order to maintain apatitic carbonate content similar to that of bone mineral [6]. In this section, thermal stability of CAP synthesized at $80^{\circ} \mathrm{C}(\mathrm{T} 80 / \mathrm{t} 48 / \mathrm{D} 4.5)$ is discussed. This solid T80/t48/D4.5 was chosen because of its lowest content of remaining $\mathrm{CaCO}_{3}$. The reactivity of solid products in SBF test, as the biomineralization activity, is also reported. This test was carried out with T80/t48/D4.5 thermally treated at the temperature range of $105-1400{ }^{\circ} \mathrm{C}$ under air atmosphere.

Thermal treatment of T80/t48/D4.5 powder was carried out in the TG-DSC analyzer under air atmosphere. The powder was heated at $10^{\circ} \mathrm{C} \mathrm{min}^{-1}$ up to desired final temperature and was kept at this temperature for $5 \mathrm{~h}$. The final temperature varied in the range $600-1400^{\circ} \mathrm{C}$. After, the oven was freely cooled down to room temperature. 

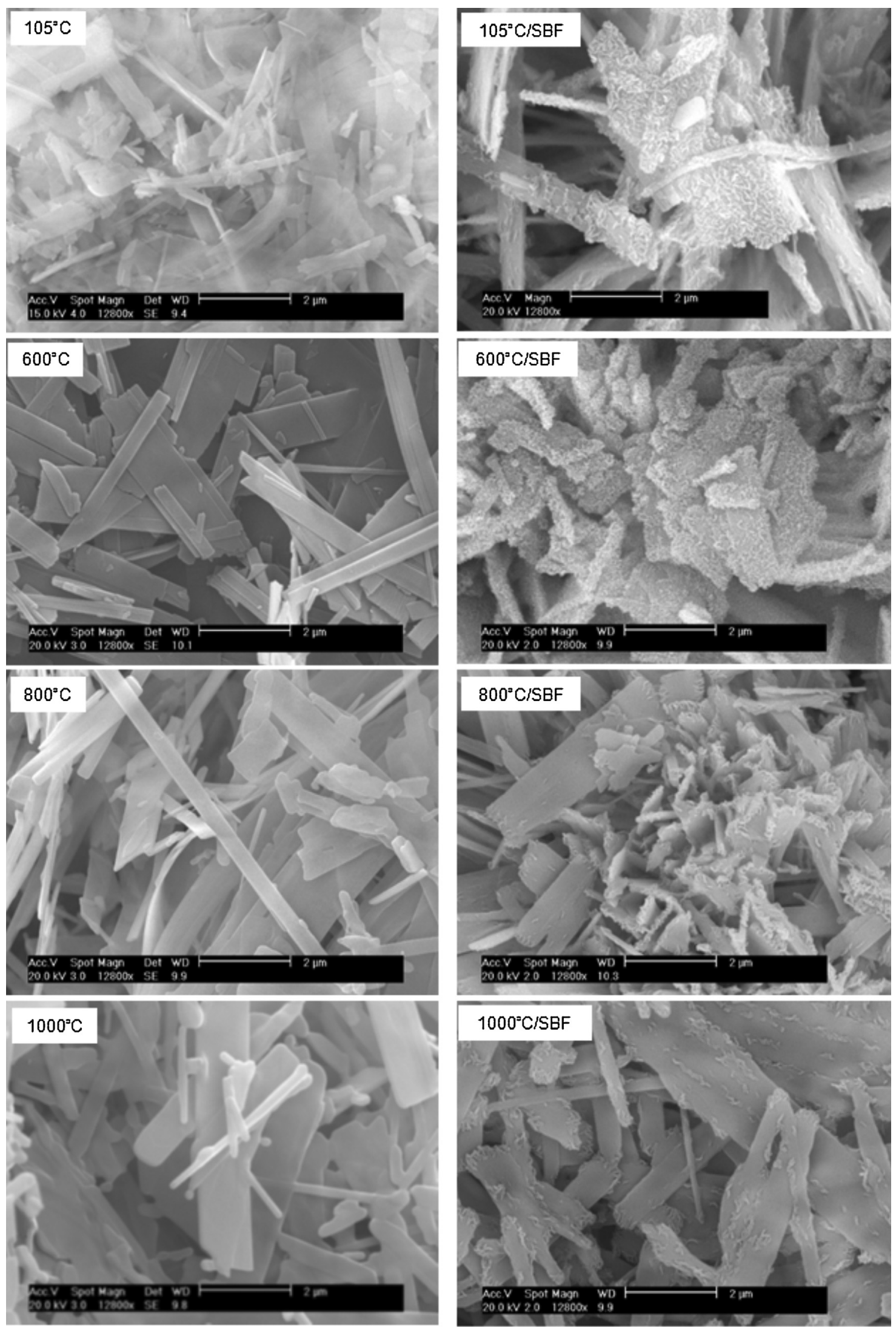

Fig. 7. SEM images of T80/t48/D4.5 treated at $105-1000^{\circ} \mathrm{C}$ before (left-hand-side) and after (right-hand-side) contact with SBF solution 

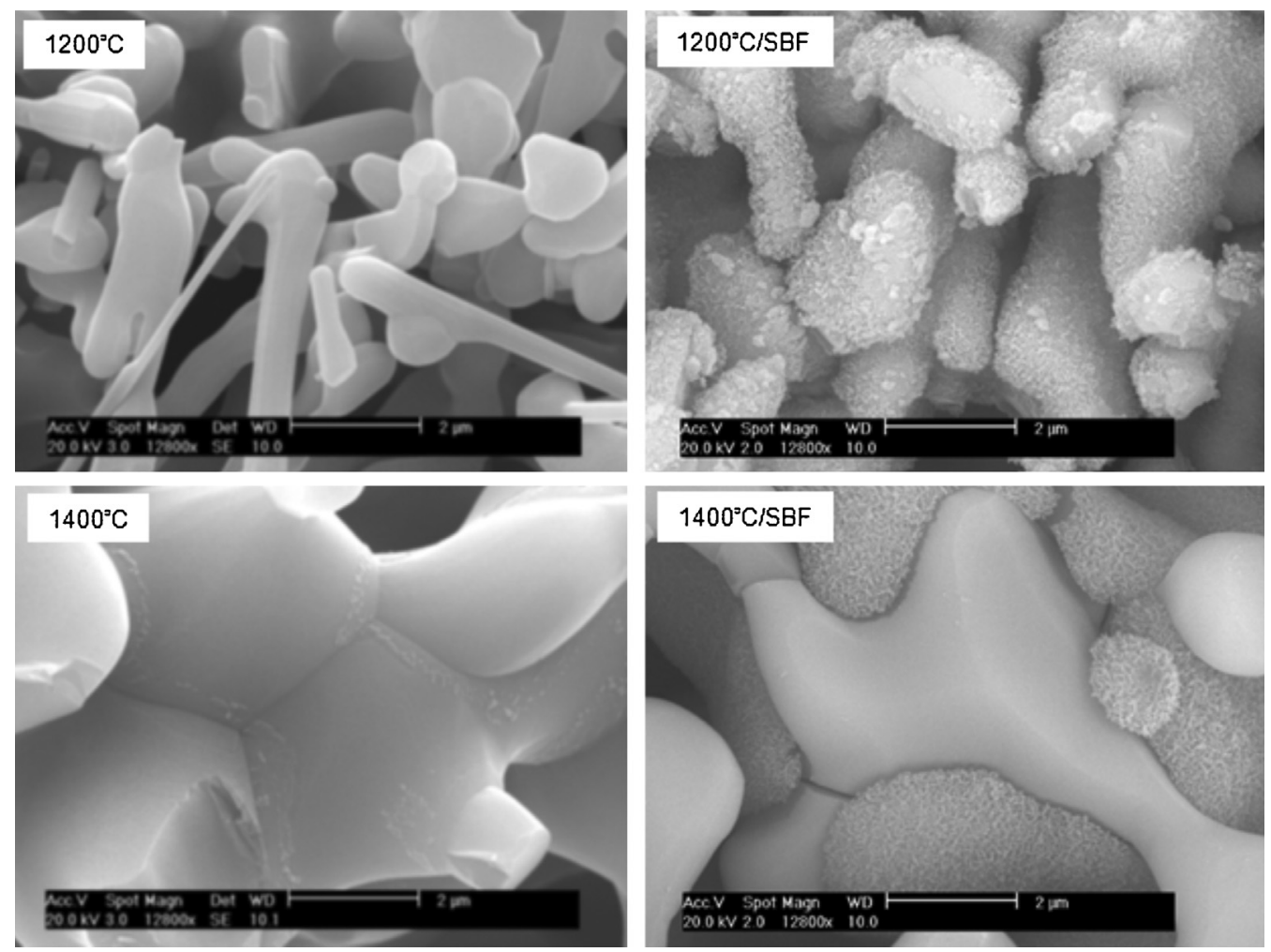

Fig. 8. SEM images of T80/t48/D4.5 treated at $1200-1400^{\circ} \mathrm{C}$ before (left-hand-side) and after (right-hand-side) contact with $\mathrm{SBF}$ solution.

IR spectra were rapidly recorded on sintered products, and are presented in Fig. 6. Although the decarbonation of CAP started around $750^{\circ} \mathrm{C}$ (TG analysis, Fig. 5), the thermal treatment in the temperature range of $600-800^{\circ} \mathrm{C}$ seemed to have no impact on the carbonate content of T80/t48/D4.5 solid. This may be explained by a low kinetic decarbonation of T80/t48/D4.5 at $600-800^{\circ} \mathrm{C}$. When the sintering temperature rose to $1000^{\circ} \mathrm{C}$, a partial decarbonation could be observed, leading to reduction of IR intensity of apatitic carbonate groups. At $1200-1400^{\circ} \mathrm{C}$, absorption bands of carbonate groups disappeared, indicating that the decarbonation was complete. The calcination at $1200^{\circ} \mathrm{C}$ led to the characteristic IR spectra of Ca-HA, while the calcination at $1400^{\circ} \mathrm{C}$ decomposed Ca-HA into tetracalcium phosphate (TTCP) and tricalcium phosphate (TCP) $[18,26]$. According to previous reports $[18,19,26]$, the thermal treatment under air atmosphere is expected to increase the crystallinities of $\mathrm{Ca}-\mathrm{HA}$ and CAP, and decrease the apatitic carbonate content of CAP, as confirmed by IR results (Fig. 6). But at the very high temperature of $1200-1400^{\circ} \mathrm{C}$, Ca-HA and CAP decomposed into TCP and TTCP.

Biomineralization activity of sintered solids was investigated using simulated body fluid (SBF) solution. Synthetic SBF solution was prepared according to previous work [27]. For this test, a solid sintered at a specific temperature was submerged into SBF solution and the obtained suspension was thermostated at $37^{\circ} \mathrm{C}$ for 7 days. SEM study was then performed on the powders recovered after rising with water and drying at room temperature.

On the left-hand-side of Fig. 7, the sintering at $600-1000^{\circ} \mathrm{C}$ had no significant influence on the apparent morphology of CAP particles. Particles of flat-needle-like morphology dominated CAP powders, dried at $105^{\circ} \mathrm{C}$ or sintered at $600-1000^{\circ} \mathrm{C}$. When the temperature rose to $1200-1400^{\circ} \mathrm{C}$ (left-hand-side, Fig. 8), sintering took place with the increase of particle size, true density and the decrease of porosity and specific surface area $[28,29]$.
For CAP powders treated at $105-1000^{\circ} \mathrm{C}$, despite the decrease of carbonate content when the calcination temperature increased as showed by TG analysis, CAP particles were covered by new calcium phosphate layers after contact with SBF solution (Fig. 7, right-hand-side). Previous reports showed that Ca-HA based materials had appropriate biomineralization activity for the growth of calcium phosphate layers in SBF solution [27,30,31]. SBF solution was also found as favorable medium for the precipitation of calcium and phosphate to form Ca-HA [32,33]. For our solid synthesized at $80^{\circ} \mathrm{C}$, the presence of trace amount of remained calcite must not influence the growth of $\mathrm{Ca}-\mathrm{HA}$ because calcite has been shown as biomineral and its growth took place in SBF solution $[14,33]$. For the solids calcined at $1200-1400^{\circ} \mathrm{C}$, although the thermal decarbonation was complete, the growth of new calcium phosphate layers also took place (Fig. 8, right-hand-side). In fact, Ca-HA, and non-apatitic calcium phosphates including TTCP and TCP, which resulted from thermal treatment of CAP at $1200-1400^{\circ} \mathrm{C}$, are also known as active biomineralization materials in SBF solution [26,31,34,35].

\section{Conclusions}

The reaction of calcite and different orthophosphates was investigated. Alkali phosphates did not allow a complete decomposition of calcite at $80^{\circ} \mathrm{C}$ in a close batch reactor.

On the other hand, orthophosphoric acid led to the complete decomposition of calcite powder, and carbonated hydroxyapatite (CAP) was formed. The reaction temperature of $80^{\circ} \mathrm{C}$ was found to be crucial for the total decomposition of calcite and thus the formation of apatitic phase. The reaction time and the dilution of calcite suspension had no significant influence on the reaction.

CAP powder starting from orthophosphoric acid and calcite was thermally stable at 600 and $800^{\circ} \mathrm{C}$ under air atmosphere. At $1000^{\circ} \mathrm{C}$ for $5 \mathrm{~h}$, partial decarbonation was observed. The 
decarbonation was total at 1200 or above. All CAP and its thermal decomposition products were found to be reactive in SBF solution, promoting crystallization of biomimetic apatites.

\section{Acknowledgment}

The authors gratefully acknowledge colleagues at RAPSODEE Center for technical help.

\section{References}

[1] E.D.M.D. Pellegrino, R.M.B.S. Biltz, Medicine 44 (1965) 397-418.

[2] K.J. Quelch, R.A. Melick, P.J. Bingham, S.M. Mercuri, Archs. Oral. Biol. 28 (1983) 665-674.

[3] J.P. Bilezikian, L.G. Raisz, T.J. Martin, Principles of Bone Biology, 3rd ed., Elsevier, 2008.

[4] E.S. Thian, Z. Ahmad, J. Huang, M.J. Edirisinghe, S.N. Jayasinghe, D.C. Ireland, R.A. Brooks, N. Rushton, W. Bonfield, S.M. Best, Biomaterials 29 (2008) 1833-1843.

[5] D. Pham Minh, N.D. Tran, A. Nzihou, P. Sharrock, Mater. Sci. Eng. C 33 (2013) 2971-2980.

[6] E. Landia, G. Celottia, G. Logroscinob, A. Tampieria, J. Eur. Ceram. Soc. 23 (2003) 2931-2937.

[7] R.M. Wilson, J.C. Elliott, S.E.P. Dowker, R.I. Smith, Biomaterials 25 (2004) $2205-2213$.

[8] S. Padilla, I. Izquierdo-Barba, M. Vallet-Regí, Chem. Mater. 20 (2008) 5942-5944.

[9] H.E. Mason, A. Kozlowski, B.L. Phillips, Chem. Mater. 20 (2008) 294-302.

[10] T. Tonegawa, T. Ikoma, Y. Suetsugu, N. Igawa, Y. Matsushita, T. Yoshioka, N. Hanagata, J. Tanaka, Mater. Sci. Eng. B 173 (2010) 171-175.

[11] W.L. Suchanek, P. Shuk, K. Byrappa, R.E. Riman, K.S. TenHuisen, V.F. Janas, Biomaterials 23 (2002) 699-710.

[12] D. Pham Minh, N.D. Tran, A. Nzihou, P. Sharrock, Ind. Eng. Chem. Res. 52 (2013) 1439-1447.

[13] D. Pham Minh, N.D. Tran, A. Nzihou, P. Sharrock, Mater. Res. Bull. 51 (2014) 236-243.
[14] M. Mozafari, F. Moztarzadeh, Challenges of spontaneous formation of calcite during bioactivity assessment on bioactive materials interfaces, in: J. Dobrev, P. Markovic (Eds.), Calcite: Formation, Properties and Applications, NOVA Science Pub Inc., New York, 2011, pp. 95-122.

[15] D. Pham Minh, N. Lyczko, H. Sebei, A. Nzihou, P. Sharrock, Mater. Sci. Eng. B 177 (2012) 1080-1089.

[16] C. Verwilghen, M. Chkir, S. Rio, A. Nzihou, P. Sharrock, G. Depelsenaire, Mater. Sci. Eng. C 29 (2009) 771-773.

[17] D. Pham Minh, H. Sebei, A. Nzihou, P. Sharrock, Chem. Eng. J. 198-199 (2012) 180-190.

[18] J.C. Elliott, Studies in Inorganic Chemistry 18: Structure and Chemistry of the Apatites and Other Calcium Orthophosphates, Elsevier, Amsterdam-LondonNew York-Tokyo, 1994.

[19] M.E. Fleet, X. Liu, Biomaterials 28 (2007) 916-926.

[20] M.E. Fleet, Biomaterials 30 (2009) 1473-1481.

[21] M. Jarcho, Clin. Orthop. Relat. Res. 157 (1981) 259-278.

[22] A.I. Mitsionis, T.C. Vaimakis, C.C. Trapalis, Ceram. Int. 36 (2010) 623-634

[23] H. Monma, Y. Nishimura, T. Okura, Phosph. Res. Bull. 18 (2005) 127-134.

[24] A. Lebugle, E. Zahidi, G. Bonel, React. Solids 2 (1986) 151-161.

[25] A. Bigi, G. Cojazzi, M. Gazzano, A. Ripamonti, N. Roveri, J. Inorg. Biochem. 40 (1990) 293-299.

[26] C.J. Liao, F.H. Lin, K.S. Chen, J.S. Sun, Biomaterials 20 (1999) 1807-1813.

[27] S. Jalota, S.B. Bhaduri, A.C. Tas, Mater. Sci. Eng. C 28 (2008) 129-140.

[28] S. Bailliez, A. Nzihou, Chem. Eng. J. 98 (2004) 141-152.

[29] D. Pham Minh, M. Galera Martinez, A. Nzihou, P. Sharrock, J. Therm. Anal. Calorim. 112 (2013) 1145-1155.

[30] T. Kokubo, S. Ito, M. Shigematsu, S. Sakka, T. Yamamuro, J. Mater. Sci. 22 (1987) 4067-4070.

[31] T. Kokubo, H. Takadama, Biomaterials 27 (2006) 2907-2915.

[32] A.C. Tas, Biomaterials 21 (2000) 1429-1438.

[33] M. Mozafari, F. Moztarzadeh, M. Tahriri, J. Non-Cryst. Solids 356 (2010) $1470-1478$.

[34] K. Kurashina, H. Kurita, M. Hirano, J.M.A. de Blieck, C.P.A.T. Klein, K. de Groot, J. Mater. Sci.: Mater. Med. 6 (1995) 340-347.

[35] L.A. Dos Santos, L.C. De Oliveira, E.C.S. Rigo, R.G. Carrodeguas, A.O. Boschi, A.C.F. De Arruda, Bone 25 (1999) 99S-102S. 